\title{
Sludge Filtration Resistance Model Based on Electrical Resistance Analogy
}

\author{
L. W. Arimieari ${ }^{1}$, J. O. Ademiluyi ${ }^{2}$ \\ ${ }^{1}$ Department of Civil Engineering, Rivers State University, Port Harcourt, Nigeria \\ ${ }^{2}$ Department of Civil Engineering, University of Nigeria, Nsukka, Nigeria \\ Email: *luvi4real@yahoo.com, professorademiluyi@yahoo.com
}

How to cite this paper: Arimieari, L.W. and Ademiluyi, J.O. (2018) Sludge Filtration Resistance Model Based on Electrical Resistance Analogy. Journal of Environmental Protection, 9, 1-12.

https://doi.org/10.4236/jep.2018.91001

Received: December 5, 2017

Accepted: January 9, 2018

Published: January 12, 2018

Copyright $\odot 2018$ by authors and Scientific Research Publishing Inc. This work is licensed under the Creative Commons Attribution International License (CC BY 4.0).

http://creativecommons.org/licenses/by/4.0/

\begin{abstract}
In this study, a model for sludge filtration resistance (SFR) was developed using electrical resistance analogy by relating the rate at which water flows to the current of charge to determine Sludge Filtration Resistance using a typical single Electrical Resistance from a Direct Current Circuit. Synthetic sludge was successfully formulated for experimental purposes. The advantage of using synthetic sludge was that they permitted experiments to be performed on stable samples with known physical and chemical properties not subject to degradation by microbial activity. The result from the present study indicates the effect of conditioner on synthetic sludge filtration at variable pressure for sludge filtration resistance (SFR) and the trends in the results indicated that SFR reduces with increase in the concentration of dissolved salt $\left(\mathrm{CaCl}_{2}\right)$. The linearity observed between plot of volume of filtrate versus time of filtration by correlation coefficient of $\mathrm{R}^{2}=0.9292$ (Figure 1) for $10 \mathrm{~g}$ of $\mathrm{CaCl}_{2}$ and $\mathrm{R}^{2}=$ 0.9294 (Figure 2) for $18 \mathrm{~g}$ of $\mathrm{CaCl}_{2}$. It is evident from the calculated values that they are very strong and have testified that the effect of conditioner on synthetic sludge filtration at variable pressure for sludge filtration resistance (SFR) using electrical resistance analogy is very satisfactory. When compared the existing data from SFR with other measure of filterability calculated using Carman's equation to validate the model, it was observed that specific resistance decreases as the concentration of $\mathrm{CaCl}_{2}$ (dissolved salt) increases which agrees with SFR.
\end{abstract}

\section{Keywords}

Sludge Dewatering, Resistance, Electrical Analogy

\section{Introduction}

Dewaterability has to do with the ease at which water is released from the sludge 
[1]. The main reason for dewatering sludge is to reduce its volume by eliminating water, which lowers transportation costs, and facilitates storage. The presence of contaminants in Sewage Sludge arising from municipal discharges is the most challenging problem and may be the deciding factor in determining the choice of a utilization dewatering option [2]. There are techniques used in dewatering devices in removing moisture from waste water sludge which include mechanical and non mechanical methods. The seeming problem in evaluating a suitable equation for filtration process depends on the sludge filtration resistance which is a parameter used in quantifying the filterability of sludge. This parameter cannot be easily measured directly like other variables normally incorporated into filtration expressions. Wastewater treatment processes result in the production of large quantities of sludge. The sludge generated is difficult to handle and dispose of because of its high water content of about 97.5 percent [3]. Dewatering process increases solid content or sludge between $20 \%$ and $35 \%$ [4] [5] [6] [7]. Typical approaches involve addition of conditioning chemicals to increase the dewatering rate and improve filtrate quality, and then processing the sludge in centrifuges, belt presses or other dewatering unit [8] [9] [10]. There are different ways to characterize the filterability of sludges. The most common method to evaluate the filterability of sludges is to determine their filterability by measuring specific resistance to filtration (SRF). The measurement of this parameter is based on the flow through a porous medium which is a good indicator of the filterability.

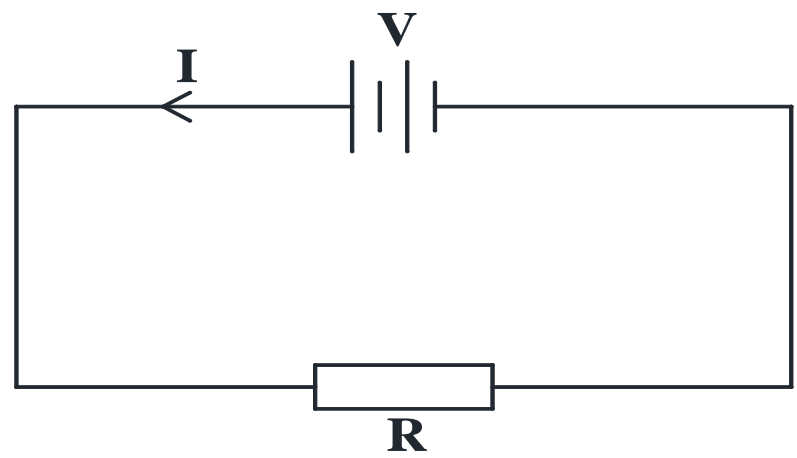

Figure 1. Electrical resistance from a direct Current (D.C) Circuit.

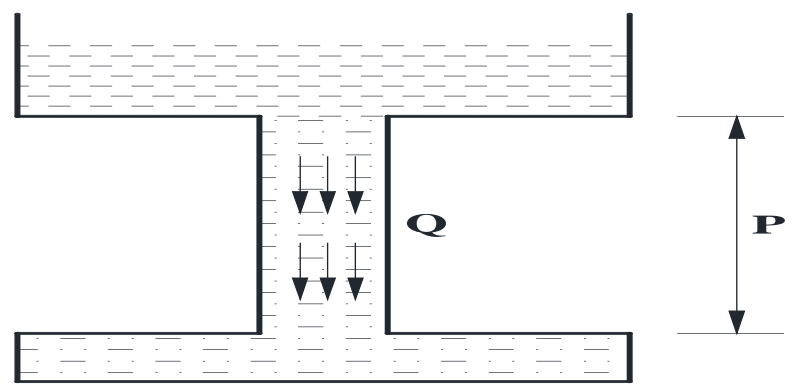

Figure 2. Relating Electrical Resistance from D.C Circuit to Sludge Filtration Resistance. 
A sludge sample that has high SRF is usually referred as difficult to dewater [11]. novel chemical surrogate for activated sludge was developed which they named synthetic sludge to study sludge dewatering, settling and conditioning characteristics made up of non-living particles that resemble activated sludge components [12].

Electricity resistance is the opposition of a conductor to current. In physics, analogy means that two or more subfields can be described by means of the same mathematical structure. The electricity quantity is analogous to the rate at which water flows is the current of charge [13]. The resistance to flow represented by a severe constriction in a water pipe is analogous to the resistance to electric current represented by a common electric "resistor" and connecting a battery to an appliance through a wire is like using a large pipe for water flow [14]. A model of filtration dewatering is presented based on the d'Arcy flow equation in which the resistance to filtration is described by the Corzeny-Carman equation and the driving force is the difference between the external pressure and the osmotic pressure of the filter cake. It has been found that this model reproduces all known features of filtration dewatering and is found to be consistent with experimental data [15]. Sludge filtration theories and derived equations have been based on experimental assumptions and conditions, each researcher making effort to modify already existing theory in order to introduce a completely new concept for evaluating sludge filtration equation. Many theories have been advanced over the years to describe this important specific resistance equation. Carman's work was based on the concept of specific resistance and the time velocity plot of sludge filtration at constant pressure. He postulated that specific resistance is independent of suspended solid concentration and assumed that the total loss of filtration pressure arises from pressure drop across filter cake, pressure drop across initial resistance and loss incurred in recovering filtrate. Carman's work has been criticized as it regards an ideal situation where the cake formed during filtration is rigid and at constant filtration pressure. Ruth established experimentally that the plot of filtrate volume $V$ versus $t$ followed a parabolic relation in line with theoretical predictions based on Carman's equations. $\mathrm{He}$ also suggested that the specific resistance in Carman's equation should be designated as an average constant value.

Thus, Carman later proposed an equation for specific resistance as [25]:

$$
r=\left(\frac{2 A^{2} P}{\mu c}\right) b
$$

where, $r=$ Specific Resistance $(\mathrm{m} / \mathrm{kg}), A=$ Area of Filtration $\left(\mathrm{m}^{2}\right), \mu=$ Viscosity of Filtrate (poise), $C=$ Mass of Dry Cake per unit Filtrate Vol., $b=$ Exponent of " $A$ " in the dimensional Partial Equation.

Ruth's equation which generally well describes the filtration sub-process [16] [17], using the slope of the line, specific resistance to filtration was calculated from the following equation derived by Ruth. 


$$
\frac{t}{V}=\left(\frac{\mu r w}{2 A^{2} P}\right) V+\frac{\mu R_{f}}{A P}
$$

where: $r=$ the specific resistance to filtration $(\mathrm{m} / \mathrm{kg}), P=$ the vacuum pressure of filtration $\left(\mathrm{N} / \mathrm{m}^{2}\right), M=$ the viscosity of filtrate (normally taken as that of water at filtrate temperature) $\left(\mathrm{N} \cdot \mathrm{s} / \mathrm{m}^{2}\right), V=$ the volume of filtrate $\left(\mathrm{m}^{3}\right), T=$ the filtration time (s), $w=$ the weight of dry solids per volume of filtrate $\left(\mathrm{kg} / \mathrm{m}^{3}\right), A=$ the area of the filter paper $\left(\mathrm{m}^{2}\right), R_{f}=$ the resistance of filter medium $\left(\mathrm{m}^{-1}\right)$.

An equation for sludge filtration was formulated based on the concept of specific resistance using LMT dimensional analysis. And the result shows that the resistance to filtration for conditioned sludge decreases as the conditioner concentration increases [2] [18]. Thus, they arrived at:

$$
R=\left(\frac{\rho g h A^{2}}{\mu C}\right) b
$$

where $R=$ specific resistance $(\mathrm{m} / \mathrm{kg}), \quad \rho g h=$ hydrostatic pressure $\left(\mathrm{N} / \mathrm{m}^{2}\right), A=$ area of filtration $\left(\mathrm{m}^{2}\right), \mu=$ the dynamic viscosity $\left(\mathrm{N} \cdot \mathrm{s} / \mathrm{m}^{2}\right), C=$ the solid content $\left(\mathrm{kg} / \mathrm{m}^{3}\right)$ and $b=$ the Slope $\left(\mathrm{s} / \mathrm{m}^{6}\right)$. An equation for sludge dewatering using FMTLxLyLz dimensional analysis based on specific resistance and compressibility [19] [20] [21]. The analysis of experimental data was in accordance with theoretical predictions. Thus,

$$
R=b\left(\frac{\rho g h A^{2} V_{s}}{\mu W_{d}}\right)
$$

$R$ is the specific resistance $(\mathrm{m} / \mathrm{kg}), A$ is the area of filtration $\left(\mathrm{m}^{2}\right), b$ is the Slope $\left(\mathrm{s} / \mathrm{m}^{6}\right), C$ is the solid content $\left(\mathrm{kg} / \mathrm{m}^{3}\right), \mu$ is the dynamic viscosity $\left(\mathrm{N} \cdot \mathrm{s} / \mathrm{m}^{2}\right), V_{s}$ is the volume of sludge $\left(\mathrm{m}^{3}\right), W_{d}$ is the weight of dry sludge $(\mathrm{kg})$ and $\rho g h$ is the hydrostatic pressure $\left(\mathrm{N} / \mathrm{m}^{2}\right)$. This study seeks to develop a model for sludge filtration resistance (SFR) using electrical resistance analogy and to compare the relationship between sludge filterability measures contributing towards the development of improved measures of sludge filterability, by evaluating the effects of modifying specified components and procedures used in the Filter Press test using synthetic sludge.

\section{Problems of Specific Resistance}

Early researchers also submitted that the specific resistance increase from the surface of the cake to the septum since the porosity decreases from the surface of the filter septum [22] [23] [24]. There is no laboratory apparatus which measures specific resistance parameter neither is there any theory simple in concept which enables the direct evaluation of specific resistance during vacuum filtration in available literature.

The expression proposed by [25] assumes the specific resistance to be constant throughout the sludge cake thickness. Specific resistance parameter in Carman's equation should be designated as an average value which was later suggested 
[26]. However, relating the variability of specific resistance along the cake thickness suggested that the concept of average specific resistance as proposed by Ruth does not make sense [27]. Therefore, it is expedient for researchers to replace the above two concepts of specific resistance based on constant and average concepts of specific resistance with a variable specific resistance concept. Carman's equation predicts that $\mathrm{v}$ is proportional to absolute area $A$ but from careful experimental investigation by [28] it has been shown that $V$ is proportional to the area A raised to the power 0.91 plus or minus 0.02 and 1.38 plus or minus 0.02 when total area and effective areas of the filter are used respectively. In Carman's equation $C$ is the mass of dry cake per unit filtrate volume and this parameter is difficult to measure experimentally as stated by [29] and hence it is taken as the initial solid content of the sludge which is inconsistent with theoretical prediction. The filtration area has brought up controversies among previous researchers which some believe that the total area should be assumed while others school of thought advocate effective area of filtration and some take the effective area as being equal to the area of the filter medium while some define it as the total area of the concentric holes of the Buchner funnel [29]. Effective filtration area of the Buchner funnel was assumed to be equal to the area of the filter paper [30]. However, this was argued that it has overestimated the true filtration area by more than $25 \%$ [31]. There is disparity in reported units of specific resistance which led to confusion and eventually hinders communication based on the fact that range of specific resistance values from raw to well conditioned sludges is the same order of magnitude as the change in numerical value of specific resistance together with the use of various units [32]. Specific resistance has been reported in seconds squared per gram, $\mathrm{S}^{2} / \mathrm{g}$ [33] [34], centimeters per gram $(\mathrm{cm} / \mathrm{g})$ and meters per kilogram, $\mathrm{m} / \mathrm{kg}$ [35] [36] [37].

\section{Materials and Methods}

\subsection{Formulation of Synthetic Sludge}

A synthetic sludge was formulated using a known quantity of the following components: Calcium chloride $\left(\mathrm{CaCl}_{2}\right)$ at various concentrations ranging from $10-18 \mathrm{~g}$ was used as a conditioner and mixed with $2 \mathrm{~g}$ of Borax, $2 \mathrm{~g}$ of Polyanionic Cellulose (PAC) and Carboxyl Methyl Cellulose (CMC) before filtration based on Laboratory barrel of fluid according to American Petroluem Institute (API) standard method. The components were dissolved in a $320 \mathrm{ml}$ of distilled water. The experiment was carried out in Petroleum Engineering Laboratory Rivers State University, Port Harcourt, Nigeria using Filter Press test apparatus according to American Petroluem Institute (API) standard method. Filter Press test apparatus is being used for measurements of filtration behaviour and wall cake-building characteristics of a drilling fluid or synthetic sludge which are fundamental to control and treatment of drilling fluids, as are various characteristics of the filtrate such as oil, water, or emulsion content. These factors are 
affected by the types and quantities of the solids in the fluid and their physical and chemical interactions, which in turn are affected by changing temperatures and pressures. The OFITE low pressure filter press helps determine filtration and wall cake-building properties of drilling fluids and is a useful tool for trend analysis in a wide range of applications. The filter press design features a cell body to hold the mud sample, a pressure inlet, a base cap with screen and filter paper, and a drain tube to discharge filtrate into a graduated cylinder. The pressure cell is designed so that a 3.5 " $(9 \mathrm{~cm})$ sheet of filter paper can be placed in the bottom of the chamber to remove particles from the fluid. The filtration area is the standard American Petroleum Institute (API) recommended filtration area of $7.1 \pm 0.1 \mathrm{in}^{2}\left(4580 \pm 60 \mathrm{~mm}^{2}\right)$. Pressure may be applied with any non-hazardous fluid medium, either gas or liquid. Some models are equipped with pressure regulators and may be pressurized with portable pressure cylinders (Nitrogen), midget pressure cartridges (Carbon Dioxide), or hydraulic pressure (clean tap water). The API recommends a standard cell pressure of $100 \pm 5$ PSI $(690 \pm 35 \mathrm{kPa})$ be applied to the fluid for a time period of 30 minutes [38]. Correlation coefficient $\left(R^{2}\right)$ was used as statistic analysis method.

\subsection{The Concept of Electrical Resistance}

Resistance is anything that will resist a current measured in Ohms named after the early 19th century German physicist George Ohm. The main formula in electrical circuit theory is Ohm's law which is proportionality constant. The electrical resistance depends on the material (bulk properties) and the geometry (length and cross-sectional area). Thereby, geometry is a controlling factor in the conducting wire design. But the calculation of resistances is a non-trivial task [39].

\subsection{Applicability of the Electrical Resistance in Cake Filtration}

Due to the inconsistency of the specific resistance units and many variable conditions that affect specific resistance which are not based on the equipment design that are difficult to control, this study seeks to draw an analogy between fluid flow rate and electrical current. Water flowing in pipes is a lot like electricity flowing in a circuit. A battery is like a pump. Electrons flowing through wires are like water flowing through pipes. The pressure generated by the pump drives water through the pipe; that pressure is like the voltage generated by the battery which drives electrons through the circuit.

\subsection{Sludge Filtration Resistance Model Using Electrical Resistance Analogy}

Electrical resistance is analogous to sludge filtration resistance relating the rate at which water flows to the current of charge. To determine the Sludge Filtration Resistance, we compare or relate its magnitude to a typical single Electrical Resistance from a Direct Current (D.C) Circuit. 
where, $V=$ Voltage, $I=$ Current and $R=$ Resistance

Similarly,

Pressure across a Sludge Resistance $=P=Q R_{e}$

$$
P=Q R_{e}
$$

where, $P=$ Pressure $\left(\mathrm{N} / \mathrm{m}^{2}\right)$

$Q=$ Volume flow rate $=V / t\left(\mathrm{~m}^{3} / \mathrm{s}\right)$

$R_{e}=$ Sludge Resistance

$V=$ Volume of filtrate

$t=$ time taken

Hence,

$$
\begin{aligned}
& P=\frac{V}{t} R_{e} \\
& V=\frac{P}{R_{e}} t
\end{aligned}
$$

Comparing this to the Equation of a straight line

$$
Y=m x+c
$$

For a graph of $V$ against $t$

$$
\begin{aligned}
& \text { Slope } b=\frac{P}{R_{e}} \\
& \therefore R_{e}=\frac{P}{b}
\end{aligned}
$$

where,

$R_{e}=$ Sludge Filtration Resistance $\left(\mathrm{N} \cdot \mathrm{s} / \mathrm{m}^{5}\right)$

$P=$ Pressure $\left(\mathrm{N} / \mathrm{m}^{2}\right)$

$b=$ Slope $\left(\mathrm{m}^{3} / \mathrm{s}\right)$

\section{Results and Discussion}

\subsection{Applicability of Electrical Resistance in Sludge Filtration Resistance}

Synthetic sludge was dewatered using the Filter Press for a five minutes interval over 30 minutes period of time at variable pressure. Sludge Filtration Resistance was determined using a plot of Volume of Filtrate $V$ versus Time of Filtration $(t)$ (Equation (8)). Using the slope of the line, Sludge Filtration Resistance was calculated using Equation (10) developed from Electrical Resistance analogy. Data generated from the filtration experiment of the effect of conditioner at different concentrations on synthetic sludge are shown in Figures 3-5.

\subsection{Comparison of SFR with Carman's Equation}

To validate the model, an experiment was conducted in order to calculate other measure of filterability. Specific resistance to filtration (R) was calculated using 


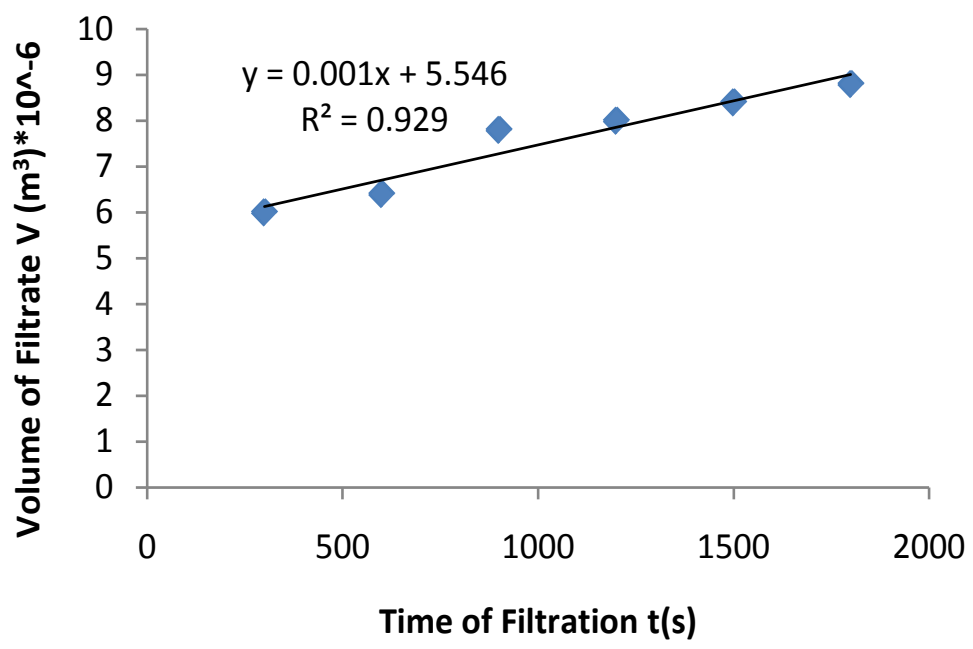

Figure 3. Plot of Volume of Filtrate versus Time of Filtration at $6.895 \times 10^{5}$ $\mathrm{N} / \mathrm{m}^{2}$ for $10 \mathrm{~g}$ of $\mathrm{CaCl}_{2}$.

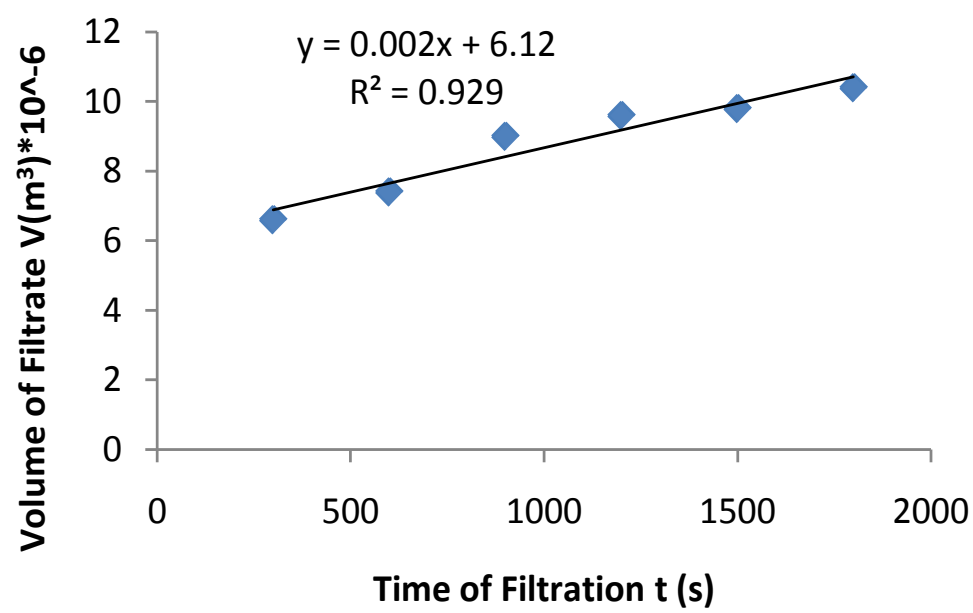

Figure 4. Plot of Volume of Filtrate versus Time of Filtration at $6.895 \times 10^{5}$ $\mathrm{N} / \mathrm{m}^{2}$ for $18 \mathrm{~g}$ of $\mathrm{CaCl}_{2}$.

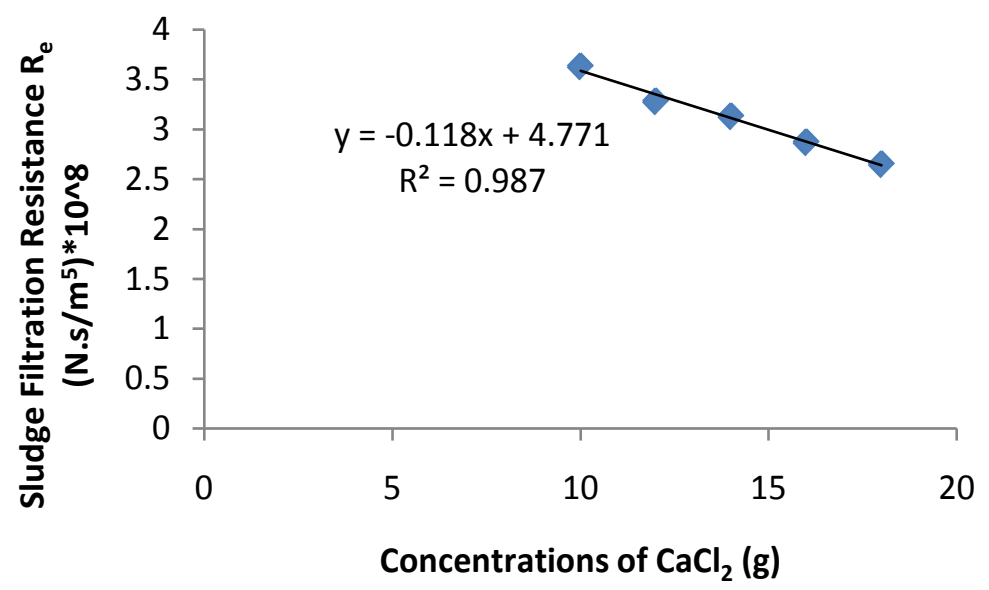

Figure 5. Plot of Sludge Filtration Resistance against Concentrations of $\mathrm{CaCl}_{2}$ at $6.895 \times 10^{5} \mathrm{~N} / \mathrm{m}^{2}$. 
Carman's equation with the R data generated for $10 \mathrm{~g}, 12 \mathrm{~g}, 14 \mathrm{~g}, 16 \mathrm{~g}$ and $18 \mathrm{~g}$ of $\mathrm{CaCl}_{2}$ as well as pressure. It was observed that specific resistance decreases as the concentration of $\mathrm{CaCl}_{2}$ (dissolved salt) increases with variation of pressure which agrees with SFR. Comparison is shown in Figure 6 and Figure 7 which gave a linear relationship.

\section{Conclusions and Recommendations}

Electrical resistance is analogous to sludge filtration resistance relating the rate at which water flows to the current of charge to determine the Sludge Filtration Resistance by comparing its magnitude to a typical single Electrical Resistance from a D.C Circuit. Synthetic sludge was successfully formulated for experimental purposes. The advantage of using synthetic sludge was that they permitted experiments to be performed on stable samples with known physical and chemical properties not subject to degradation by microbial activity. The linearity

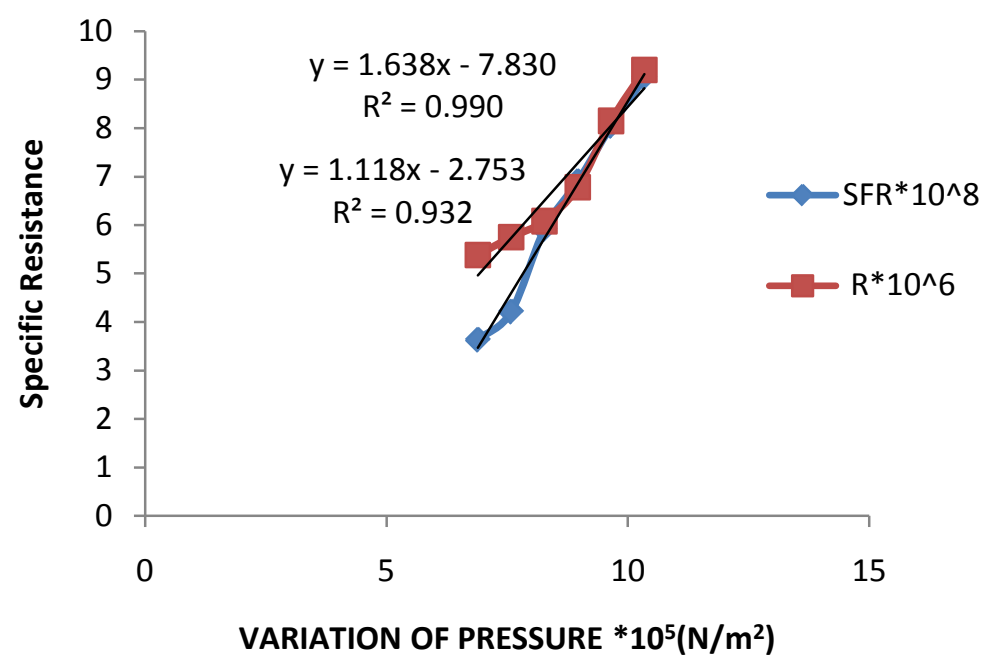

Figure 6. Comparison of SFR with R Carman's equation for variation of Pressure at $10 \mathrm{~g}$ of $\mathrm{CaCl}_{2}$.

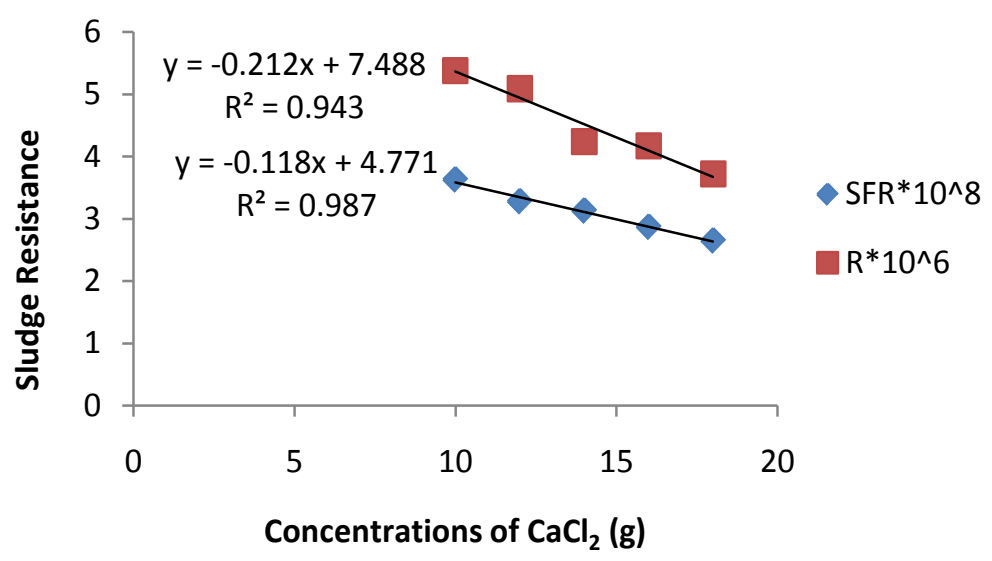

Figure 7. Comparison of SFR with R Carman's equation against Concentrations of $\mathrm{CaCl}_{2}$. 
observed between plot of volume of filtrate versus time of filtration by correlation coefficient of $R^{2}=0.9292$ (Figure 3) for $10 \mathrm{~g}$ of $\mathrm{CaCl}_{2}$ and $R^{2}=0.9294$ (Figure 4) for $18 \mathrm{~g}$ of $\mathrm{CaCl}_{2}$. The trends in the results indicated that the greater the concentration of dissolved salt $\left(\mathrm{CaCl}_{2}\right)$, the lower Sludge filtration resistance (SFR) using Equation (10). The main purpose of conducting SFR tests at wastewater treatment plants is to save operating costs by evaluating the optimal dose of the sludge conditioner, which is the dose of coagulant that produces the minimal resistance to filtration. Sludge conditioning enhances the formation of dense flocs so that the solids can be more easily separated by subsequent dewatering processes. Conditioning is important in order to improve the efficiency of the dewatering equipment. Lower operating costs are achieved if the most efficient conditioning and dewatering processes are used taking into account the reduction in the cost of dewatering that can be achieved and the cost of dosing with the conditioner. During optimization of sludge treatment, it is possible to obtain considerable savings or losses simply through increased or decreased use of conditioners. Inefficient conditioner dosage is the major cause of excessive operating costs if not made up to the correct dilution and dosed at the correct rate then the sludge may be dampened than optimum for the dewatering process and the plant operating costs are lifted resulting in wasted energy and more environmental damage. When compared the existing data from SFR with other measure of filterability calculated using Carman's equation to validate the model, it was observed that specific resistance decreases as the concentration of $\mathrm{CaCl}_{2}$ (dissolved salt) increases which agrees with SFR. The model developed should be applied in design of dewatering processes for effective management of wastes. Other researchers are encouraged to carry out further research on synthetic sludge for improvement.

\section{References}

[1] Sanin, F.D., Clarkson, W.W. and Vesilind, P.A. (2011) Sludge Engineering: The Treatment and Disposal of Wastewater Sludges. DEStech Publications, Inc. Lancaster, PA.

[2] Ademiluyi, J.O. and Arimieari, L.W. (2012) Evaluating the Specific Resistance of Conditioned Sludge Filtration on Natural Drying Bed. International Journal of Current Research, 4, 157-161.

[3] Garg, S.K. (2008) Sewage Disposal and Air Pollution Engineering. Khanna Publishers; 2-B, Nath Market, Nai Sarak, Delhi, 401-404.

[4] Agunwamba, J.C. (2001) Waste Engineering and Management Tools. Immaculate Publication Ltd., Enugu, p. 186.

[5] Hammer, M.J. and Hammer Jr., M.J. (2000) Water and Wastewater Technology. Prentice-Hall of India Private Limited, New Delhi, 275-276, 421-430.

[6] Klingel, F., Montangero, A., Kone, D. and Strauss, M. (2002) A Planning Manual on Fecal Sludge Management. Swiss Federal Institute for Environmental Science and Technology Department for Water and Sanitation in Developing Countries.

[7] Wu, Q. (2003) Mathematical Modeling Analysis of Floating Bead Biofilter Applications to Domestic Wastewater Treatment. A Master of Science Thesis in Civil Engi- 
neering. Submitted to the Graduate Faculty of the Louisiana State University and Agricultural and Mechanical College.

[8] Octavio, P.S. (2007) Impact of Sludge Pre-Digestion: Disintegration on Dewatering and Polymer Dose. M.Sc. Thesis, Centre for Water Science, Cranfield University, 1-2.

[9] Hakim, S. and Leila, M. (2006) Simulation of a Series of Industrial Slurry Reactors for HDPE Polymerization Process Using Deconvolution of the GPC Graph of Only the First Reactor. Iranian Polymer Journal, 15, 655-666.

[10] Jamal, A.R. and Kamel, K.A. (2011) Increase the Efficiency of Conventional Sand Drying Beds by Using Intensive Solar Energy: A Case Study from Jordan. 2nd International Conference on Environmental Science and Technology IPCBEE, Vol. 6, IACSIT Press, Singapore.

[11] Emir, E.Ü. (2002) The Role of Dewaterability Measures on the Liquid-solid Separation of Biological Sludges: Compactibility as a New Measure of Sludge Dewaterability Bogazici University. Institute of Environmental Sciences, Filters and Filtration, $166 \mathrm{p}$.

[12] Sanin, F.D. and Vesilind, P.A. (1996) Synthetic Sludge: A Physical/Chemical Model in Understanding Bioflocculation. Water Environment Research, 68, 927-933. https://doi.org/10.2175/106143096X127938

[13] Fuchs, H.U. (2010) The Dynamics of Heat: A Unified Approach to Thermodynamics and Heat Transfer. Graduate Texts in Physics, Springer Science+Business Media, LLC. https://doi.org/10.1007/978-1-4419-7604-8

[14] Nave, C.R. (2008) Water Circuit Analogy to Electric Circuit Part 1, Hyper Physics. Georgia State University, Atlanta, GA.

[15] Keiding, K. and Rasmussenb, M.R. (2003) Osmotic Effects in Sludge Dewatering. Advances in Environmental Research, 7, 641-645. https://doi.org/10.1016/S1093-0191(02)00043-6

[16] Attar, M.H., Bina, B. and Moeinian, K. (2005) Effects of Aeration Rate and Detention Time on Thermophilic Aerobic Digestion of Mixed Sludge and Its Dewaterability. International Journal of Environmental Science and Technology, 2, 105-111. https://doi.org/10.1007/BF03325864

[17] Viessman, W. and Hammer, M. (1985) Water Supply and Pollution Control. 4th Edition, Harper and Row Publishers, New York.

[18] Anazodo, U.G.N. (1975) Dimensional Equation for Sludge Filtration. Effluent and Water Treatment Journal, 422-423.

[19] Ademiluyi, J.O. and Eze, B.I. (2014) FMTLxLyLz Dimensional Equation for Sludge Drying Beds. Nigerian Journal of Technology, 33, 367-374. https://doi.org/10.4314/njt.v33i3.15

[20] Onosakponome, O.R. and Onyejekwe, S.C. (2014) Systematic Modeling of Sludge Filtration Process using Dimensional Analysis Technique. International Journal of Engineering Research and Applications, 4, 43-53.

[21] Afangiden, C.B., Offiong, A. and Ademiluyi, J.O. (2014) Comparative Study of the LTM and FLMT Dimensional Equations for Sludge Filtration. Journal of Engineering and Applied Sciences, 9, 224-230.

[22] Grace, H.P. (1953) Resistance and Compressibility of Filter Cakes. Chemical Engineering Progress, 49, 303-318.

[23] Tiller, F.M. and Shirato, M. (1964) The Role of Porosity in Filtration: Part VI New Definition of Filtration Resistance. Journal of American Institute of Chemical Engineers, 10, 61-67. 
[24] Hemant, R.M. (1981) Cake Filtration Empirically Incorporating Particle Migration. Filtration and Separation, 18, 20-24.

[25] Carman, P.C. (1934) A Study of the Mechanism of Filtration Part 111. Journal of the Society of Chemical Industry, Transactions and Communications, 53, 159T-165T.

[26] Ruth, B.F. (1935) Studies in Filtration Derivation of General Filtration Equation. Industrial and Engineering Chemistry, 25, 76-82.

[27] Shirato, M. and Tsutomu, A. (1972) Verification of Internal Flow Mechanism Theory of Cake Filtration. Filtration and Separation, 9, 290-297.

[28] Ademiluyi, J.O., Anazodo, U.G.N. and Egbuniwe, N. (1982) Filterability and Compressibility of Sludges, Part 1. Effluent and Water Treatment Journal, 22, 428-431.

[29] Ademiluyi, J.O. (1981) The Filterability and Compressibility of Domestic, Agricultural and Industrial Sludges. M.Sc. Thesis, University of Nigeria, Nsukka, 105 p.

[30] Coackley, P. (1958) Laboratory Scale Filtration Experiments and Their Application to Sewage Sludge Dewatering. In: Mccabe and Eckenfelder, Eds., Biological Treatment of Sewage and Industrial Wastes, Reinhold Pub. Corp., New York, 270-290.

[31] Swanwick, J.O. and Marian, F.M. (1961) Determination of Specific Resistance to Filtration. Water and Waste Treatment, 8, 386-389.

[32] Christensen, G.L. (1983) Units for Specific Resistance. Water Environment Federation, 55, 417-418.

[33] Pietila, K.A. and Jobert, P.J. (1981) Examination of Process Parameters Affecting Sludge Dewatering with a Diaphragm Filter Press. Journal of Water Pollution Control Federation, 53, 1708-1716.

[34] Wu, Y.O., Smith, D. and Novak, R. (1982) Filtrability of Activated Sludge in Response to Growth Conditions. Journal of Water Pollution Control Federation, 54, 444-456.

[35] Purchas, D.B. (1980) A Practical View of Filtration Theory. Filtration and Separation, 17, 147-151.

[36] Alsop, G.M. and Conway, R.A. (1982) Improved Thermal Sludge Conditioning by Treatment with Acids and Bases. Journal (Water Pollution Control Federation), 54, 146-152.

[37] Knocke, W.R., Ghosh, M.M. and Novak, T.J. (1983) Vacuum Filtration of Metal Hydroxide Sludges. Journal of Environmental Engineering Division, 106, 363-376.

[38] OFI Testing Equipment, Inc. Filter Press with $\mathrm{CO}_{2}$ Assembly Instruction Manual Updated 12/30/2014 Ver. 2.5. Houston. http://www.ofite.com

[39] Rodriguez-Valverde, M.A. and Tirado-Miranda, M. (2009) A Simpler Derivation of the Integral Formula of Electrical Resistance. European Journal of Physics, 30, L47-L50. https://doi.org/10.1088/0143-0807/30/4/L01 